\title{
Diosgenin inhibits cell proliferation of primary human thyrocytes via downregulation of PI3K/Akt signaling pathway
}

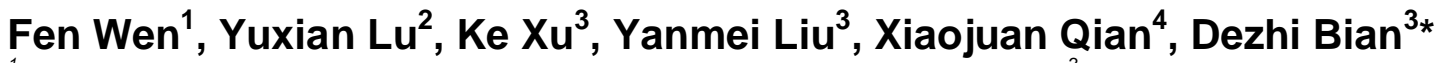 \\ ${ }^{1}$ Department of Oncology, Yancheng First People's Hospital, Yancheng, 224006, ${ }^{2}$ School of Nursing, Jiangsu Vocational \\ College Medicine, Yancheng, 224005, ${ }^{3}$ Department of Endocrine, Yancheng First People's Hospital, Yancheng, 224006, \\ ${ }^{4}$ Clinical College, Jiangsu Vocational College Medicine, Yancheng, 224005
}

*For correspondence: Email: dezhiBian2008@163.com

Sent for review: 16 December 2017

Revised accepted: 20 June 2018

\begin{abstract}
Purpose: To determine the potential influence of diosgenin on proliferation of human thyrocytes and its possible mechanism.

Methods: Primary human thyrocytes were cultured and treated with diosgenin at various time intervals. Anti-proliferative activity was determined by MTT assay. Cell proliferation was evaluated by EdU assay while cell cycle was analyzed using fluorescence-activated cell sorting (FACS) method. Protein expression of p21 (CIP1), p27 (KIP1), cyclins, protein kinase B (Akt), phosphatidylinositol 3 kinase (PI3K) and p-Akt was determined by the western blot.

Results: Diosgenin inhibited proliferation of primary human thyrocytes and caused G0/G1 arrest in a concentration-dependent manner. It also downregulated cyclin D1 and phosphorylation of PI3K and Akt, but upregulated p21 and p27.

Conclusion: Inhibition of proliferation of primary human thyrocytes by diosgenin occurs via downregulation of PIJKJAkt signaling pathway. Therefore, diosgenin can be developed as a potential drug for the treatment of thyroid disease.
\end{abstract}

Keywords: Diosgenin, Proliferation, Primary human thyrocytes, PI3K/Akt signaling pathway

\begin{abstract}
This is an Open Access article that uses a funding model which does not charge readers or their institutions for access and distributed under the terms of the Creative Commons Attribution License (http://creativecommons.org/licenses/by/4.0) and the Budapest Open Access Initiative (http://www.budapestopenaccessinitiative.org/read), which permit unrestricted use, distribution, and reproduction in any medium, provided the original work is properly credited.

Tropical Journal of Pharmaceutical Research is indexed by Science Citation Index (SciSearch), Scopus, International Pharmaceutical Abstract, Chemical Abstracts, Embase, Index Copernicus, EBSCO, African Index Medicus, JournalSeek, Journal Citation Reports/Science Edition, Directory of Open Access Journals (DOAJ), African Journal Online, Bioline International, Open-J-Gate and Pharmacy Abstracts
\end{abstract}

\section{INTRODUCTION}

Graves' disease (GD) is a common autoimmune thyroid disease. Diffusion of thyroid goiter is a characteristic feature of GD in which cell proliferation is important in the pathogenesis, as the size of thyroid is proportional to the length of time of GD medical treatment [1]. It is hence important to explore the mechanism for thyroid goiter formation to find effective therapies for GD.
Instead of using radioactive iodine and thyroid surgery, antithyroid drugs, including carbimazole, methimazole, and propylthiouracil are the mainstream therapies for uncomplicated GD [2]. There are, however, drawbacks of these treatments including high recurrence, long treatment course and low remission rate for large goiters. Antithyroid drugs inhibit synthesis of thyroid hormone in large goiter; however, they 
are sometimes non-effective in remitting goiter and often cause mental stress on patients [3]. Anti-proliferative approaches might be a better way to treat GD, especially for large goiters, but such approaches have not been studied yet.

Diosgenin, originally extracted from wild yam roots (Dioscorea villosa) [4], is a steroidal saponin also found in plants such as Dioscorea species, fenugreek and Costus speciosus [5]. Diosgenin is traditionally used for diabetes treatment [6], skin aging [7], hypercholesterolemia [8], and gastrointestinal ailments [9]. It exhibits various biological activities, including anticancer activity, cardiovascular protection, anti-diabetic activity, neuroprotection, immunomodulation, and skin protection [10]. The inhibitory effect of diosgenin on thyrocyte proliferation has also been previously described [11]; however, it is not clear if diosgenin exerts any effects on human thyroid follicles.

This work aimed to evaluate the role of diosgenin on proliferation of primary human thyroid cells and to explore the mechanism of its action.

\section{EXPERIMENTAL}

\section{Thyroid cell culture}

Human thyrocytes were from euthyroid patients who had benign follicular nodules surgery. Dissected and minced tissues were used in the experiments. Reagents used were purchased from Sigma-Aldrich (San Francisco, USA) unless otherwise stated. The resulting samples were centrifuged at $500 \mathrm{~g}$ in $\mathrm{Ca}^{2+} / \mathrm{Mg}^{2+}$-free Hanks' salt solution, in which the samples were then shaken with type I collagenase (200 units/mL), trypsin $(0.25 \%)$ and heat-inactivated dialyzed chicken serum (GIBCO, $0.75 \mathrm{mg} / \mathrm{mL}$ ) at $37^{\circ} \mathrm{C}$ for $60 \mathrm{~min}$. Supernatant was washed with Dulbecco's Modified Eagle Medium (DMEM) and F12 culture medium and then centrifuged at $500 \mathrm{~g} \mathrm{[12].}$

The resulting tissues were added to a mixture of DMEM and F12 culture media supplemented with new-born bovine serum (NBS, $10 \%$ ), thyroid stimulating hormone (TSH, $2 \mathrm{~m}$ units $/ \mathrm{mL}$ ), penicillin (100 units $/ \mathrm{mL})$, streptomycin (100 units $/ \mathrm{mL})$ and amphotericin B $(2 \mu \mathrm{g} / \mathrm{mL})$. Cells were maintained in DMEM/F12 media for primary culture and were kept at $37^{\circ} \mathrm{C}$ in a humidified atmosphere with $5 \% \mathrm{CO}_{2}$. Supernatant was removed 24 h subsequent to incubation. Within 5 days, the cells were observed to reach $70-80 \%$ confluence. Consent was obtained from all and the experimental method was approved by Yancheng First People's Hospital Ethics Committee (ethics ref no. 2014011) and also followed both the guidelines of WHO International Code of Ethics for Human Biomedical Research and Helsinki Declaration $[13,14]$.

\section{3-(4,5-Dimethylthiazolyl-2)-2,5- diphenyltetrazolium bromide (MTT) assay}

Anti-proliferative activity of diosgenin was measured using MTT assay. Cells were seeded in 96-well microtiter plates (8000 cells/well) and were incubated for $24 \mathrm{~h}$, after which the growth medium was replaced with DMEM/F12 (supplemented with NBS (0.2\%), penicillin, streptomycin and amphotericin B) in which the cells were starved at $37^{\circ} \mathrm{C}$ overnight. Diosgenin was added to the cells at 24, 48 and $72 \mathrm{~h}$, respectively. MTT solution (10 $\mu \mathrm{L}, 12 \mathrm{mM}$, Beyotime, China) was added to each well with cells and the same amount of MTT solution was added to the pure medium as the negative control. Posterior to the complete formation of formazan crystal dimethyl sulfoxide (DMSO, 10 $\mu \mathrm{L})$ was added. Absorbance was determined in a spectrophotometer at a wavelength of $570 \mathrm{~nm}$.

\section{5-Ethynyl-2'-deoxyuridine (EdU) assay}

The influence of diosgenin on proliferation of primary human thyrocyte cells were assessed using the EdU assay kit (Ribobio, China). Thyrocytes were maintained in 96-well plates. To the cells diosgenin was added subsequent to overnight starvation and were left incubating for 24 or $48 \mathrm{~h}$. EdU (50 $\mu \mathrm{M} / \mathrm{L})$ was added to the cells and incubated at $37{ }^{\circ} \mathrm{C}$ for $4 \mathrm{~h}$, after which formaldehyde (4\%) was added to fix the cells, which were left at room temperature $\left(20-25^{\circ} \mathrm{C}\right)$ for $30 \mathrm{~min}$. The following Triton X-100 (0.5\%) treatment lasted for 20 min for permeabilization. The permeabilized cells were then treated with Apollo ${ }^{\circledR}$ reaction cocktail $(100 \mu \mathrm{L} /$ well $)$ and incubated for $30 \mathrm{~min}$ subsequent to washing the cells with PBS. DNA-staining with bisbenzimide $(100 \mu \mathrm{L}, 5 \mu \mathrm{g} / \mathrm{mL})$ was carried out and then left for $30 \mathrm{~min}$ and examined under microscope.

\section{Flow cytometry: fluorescence-activated cell sorting (FACS)}

Cell cycle was analyzed by FACS. Diosgenin was added after overnight starvation to the cells, which were harvested and stained with propidium iodide (Beckman Coulter, USA). The resulting cells were examined on EPICS Elite ESP (Beckman Coulter, USA). Ratios of cells in different growth phases, $G_{0} / G_{1}, S$, and $G_{2} / M$, were calculated and processed using the Coulter's Cytologic. 


\section{SDS-PAGE and western blot}

Pre-washed (with PBS) cells were lysed in RIPA buffer at $0{ }^{\circ} \mathrm{C}$ for $20 \mathrm{~min}$. The resulting protein lysates were centrifuged at a speed of 12,000 $\mathrm{rpm}$ at $4{ }^{\circ} \mathrm{C}$ for $10 \mathrm{~min}$, after which the supernatants at upper layer were either used immediately or preserved at $-80{ }^{\circ} \mathrm{C}$. Concentrations of protein were determined using the bicinchoninic acid assay (Pierce, USA). 40 $\mu \mathrm{g}$ of protein was heated at $60^{\circ} \mathrm{C}$ for $30 \mathrm{~min}$ for each sample and separated by SDS-PAGE.

The separated protein was transferred onto nitrocellulose membranes, which were then blocked with $5 \%$ skimmed milk for $1 \mathrm{~h}$ and then kept at $4{ }^{\circ} \mathrm{C}$ overnight with primary antibodies (cyclin D1 (1: 400), cyclin B1 (1: 1000), PI3K (1: 600), Akt (1: 400), p21 (1: 600), p27 (1: 600), or ABCAM (1:600)). All antibodies were purchased from Abcam (Cambridge, UK). The washed membranes were incubated with the corresponding secondary antibodies.

The enhanced chemiluminescence (ECL) was used to visualize the results and the bands were developed using Alphalmager 2200. Data were adjusted according to the internal control ( $\beta$ actin).

\section{Data processing}

Data are reported as mean \pm SD $(n=3)$ and were analyzed using SPSS 18.0 (SPSS Inc., Chicago, IL). Student t-test was used to determine statistical significance with $p<0.05$ considered statistically significant.

\section{RESULTS}

\section{Effects of diosgenin on cell proliferation}

Diosgenin's influence on primary human thyrocytes was examined: cell viability was not interrupted significantly when $15 \mu \mathrm{M}$ of diosgenin was used for $24 \mathrm{~h}$, while $20 \mu \mathrm{M}$ of diosgenin inhibited cell proliferation $(p<0.001)-$ a concentration- and time-dependent manner was thus concluded (Figure 1).

EdU assay was used to examine the influence of diosgenin on cell proliferation. It was found that EdU-positive cells significantly reduced in number in the diosgenin-treated group (Figure 2 A), in an apparent concentration-dependent and time-dependent manner (Figure $2 \mathrm{~B}$ ).

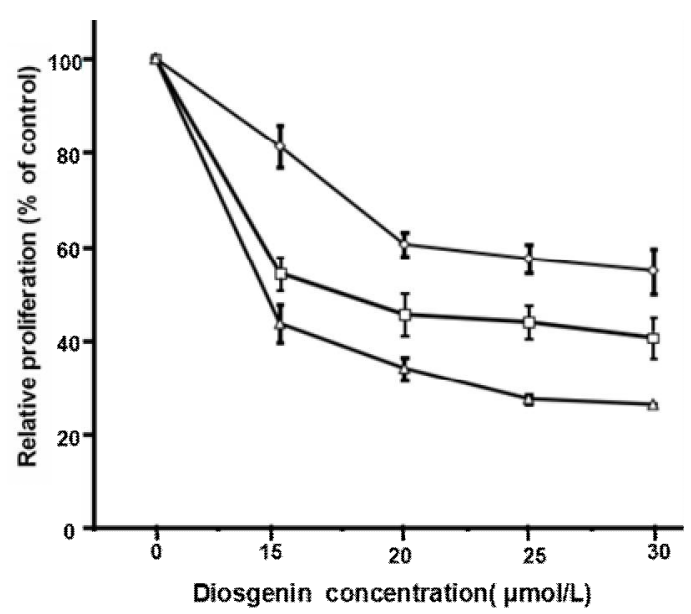

Figure 1: Influence of diosgenin on cell viability. Results were presented as ratio, relative to a negative control with culture medium only. $\diamond=$ treatment for 24 $\mathrm{h} ; \square=$ treatment for $48 \mathrm{~h} ; \Delta=$ treatment for $72 \mathrm{~h}$

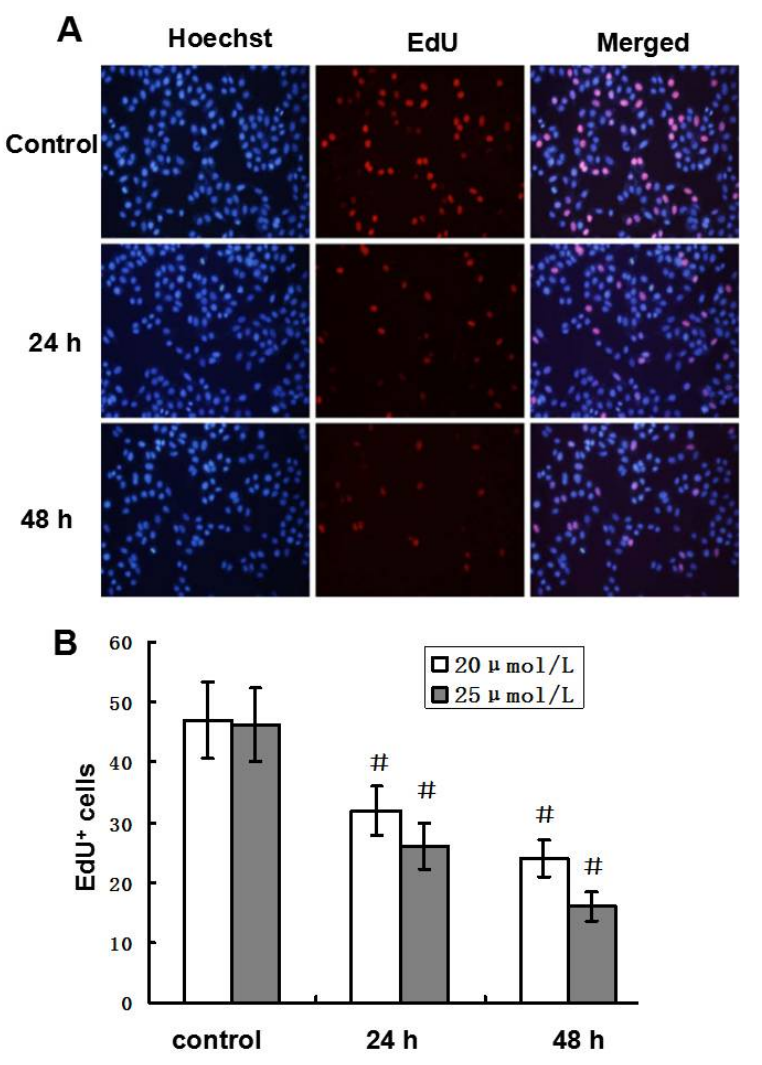

Figure 2: Diosgenin inhibited cellular DNA replication in primary human thyrocytes( HP: 200x). (A) Fluorescent staining showed incorporation of EdU in thyrocytes co-cultured with diosgenin for 24 and $48 \mathrm{~h}$. (B) EdU-positive cells after 24/48 h of treatment was obtained using five consecutive visual fields $(p<0.05)$

\section{Influence of diosgenin on cell cycle analyzed by FACS}

Thyrocytes were incubated in the growth medium supplemented with NBS $(0.2 \%)$ for $48 \mathrm{~h}$ in order to initiate quiescent after overnight starvation. 25 
$\mu \mathrm{mol} / \mathrm{L}$ diosgenin was added to the cells, which were left for 24,48 , and $72 \mathrm{~h}$ of incubation, respectively. More cells in $\mathrm{G}_{0} / \mathrm{G}_{1}$ phase and fewer in $S$ phase were observed in diosgenintreated groups compared to the control group. However, the number of cells in $\mathrm{G}_{2} / \mathrm{M}$ phase remained unchanged (Figure 3 , Table 1 ).
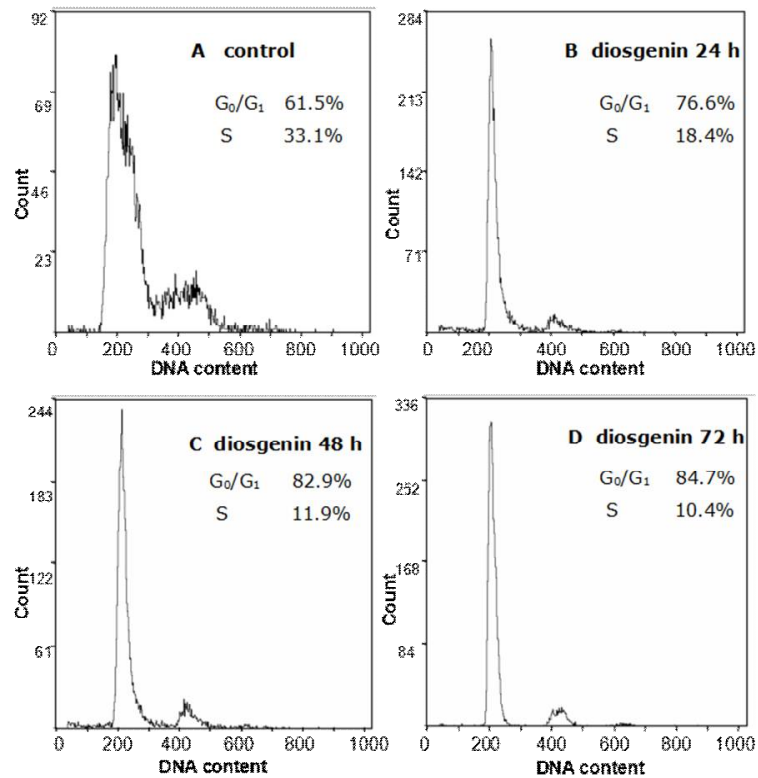

Figure 3: Effect of diosgenin on cell cycle. Thyrocytes were incubated $(A)$ for $48 \mathrm{~h}$ in the control group or $(B)$ were exposed to diosgenin $(25 \mu \mathrm{M})$ for $12 \mathrm{~h}$ for $(\mathrm{C}) 24$ $\mathrm{h}(\mathrm{D})$ for $48 \mathrm{~h}$

\section{Effect of diosgenin on protein expression}

Western blot was used to examine diosgenin's influence on protein expression. Diosgenin (25 $\mu \mathrm{M})$ was incubated with primary human thyrocytes for different periods of time. It was found that after 6,12 and $24 \mathrm{~h}$ of diosgenin treatment, lower expression levels of PI3K, $p$ $\mathrm{PI} 3 \mathrm{~K}$, and $\mathrm{p}$-Akt protein, but higher expression levels of p21 and p27, than the control group were observed. However, the protein level of Akt remained unchanged (Figure $4 \mathrm{~A}$ ). Interestingly, cyclin D1 protein expression was not disrupted by diosgenin treatment for $6 \mathrm{~h}$, whereas a 12- or 24-h diosgenin treatment decreased the expression of cyclin D1 (Figure 4B). Protein levels of cyclin B1, ERK, $p$-ERK, MEK and $p$ -
MEK were similar in each group after the diosgenin treatment (Figure $4 \mathrm{C}$ ).
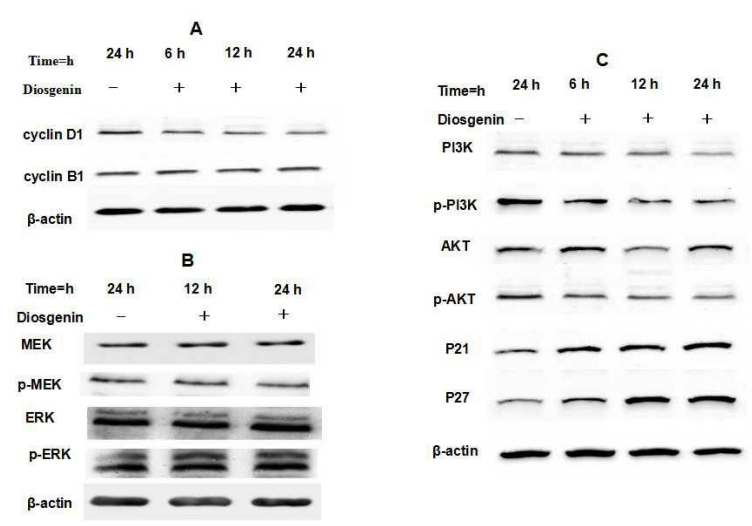

Figure 4: Effect of diosgenin on expression level of proteins. Thyrocytes were incubated with diosgenin $(25 \mu \mathrm{M})(\mathrm{A}, \mathrm{C})$ for 6,12 or $24 \mathrm{~h}(\mathrm{~B})$ were exposed to diosgenin $(25 \mu \mathrm{M})$ for 12 or $24 \mathrm{~h}$

\section{DISCUSSION}

In this study, inhibitory effects of diosgenin in primary human thyrocytes was examined and the possible mechanism for diosgenin action was investigated. It was found that the cell proliferation was halted upon addition of diosgenin and cell cycle was arrested at $G_{0} / G_{1}$, and that the anti-proliferative activity of diosgenin might involve the PI3K/Akt and MAPK signaling pathways.

Diosgenin was shown to inhibit the proliferation of primary human thyrocytes in both concentration- and time-dependent manners, consistent with the previous studies [15]. The potency of inhibition by the same concentration of diosgenin was however different in our experiments. This might be due to the cell typespecific responses to diosgenin.

Cell cycle is a common target of cancer therapies as it regulates the growth, proliferation, and death of cells, and is co-regulated by cyclins, cyclin-dependent kinases (CDKs) and their inhibitors. CDKs regulated transitions between cell cycle phases and are also involved in cell cycle arrest [16].

Table 1: Effect of diosgenin on cell cycle

\begin{tabular}{lcccc}
\hline Variable & Control & $\begin{array}{c}\text { Diosgenin2 } \\
\mathbf{4 ~ h}\end{array}$ & $\begin{array}{c}\text { Diosgenin4 } \\
\mathbf{8} \mathbf{~ h}\end{array}$ & $\begin{array}{c}\text { Diosgenin } \\
\mathbf{7 2 ~} \mathbf{~ h}\end{array}$ \\
\hline $\mathrm{G}_{0} / \mathrm{G}_{1}$ & $61.5 \pm 5.8$ & $76.6 \pm 4.6^{*}$ & $82.9 \pm 3.3^{*}$ & $84.7 \pm 4.4^{*}$ \\
$\mathrm{~S}$ & $33.1 \pm 4.9$ & $18.4 \pm 4.4^{*}$ & $11.9 \pm 2.1^{*}$ & $10.4 \pm 3.2^{*}$ \\
$\mathrm{G}_{2} / \mathrm{M}$ & $5.4 \pm 0.5$ & $5.0 \pm 1.6$ & $5.2 \pm 1.8$ & $5.1 \pm 0.4$ \\
\hline${ }^{*}$ Compared with control $(p<0.05)$ & & &
\end{tabular}


Our results demonstrated that diosgenin exposure triggered cell cycle arrest at $\mathrm{G}_{0} / \mathrm{G}_{1}$, as well as decreased expression of cyclin D1. Cyclin D1 acted as a rate-limiting component in cell cycle progression with which its expression varied whereas cyclin $B 1$ regulated $G_{2} / M$ checkpoint [17]. The research indicated that diosgenin arrested cell cycle via downregulating cyclin D1.

The anti-proliferative activity of diosgenin was shown by both arrest of cell cycle and trigger of apoptosis in some cancers [18]. In addition, cell cycle arrest is also associated with downregulation of TNF-induced expression of cyclin D1 [19]. Additionally, diosgenin arrested breast cancer stem-like cells in sub-G $\mathrm{G}_{1}$ phase [17]. Our results suggested that diosgenin arrested cell cycle of primary human thyrocytes by downregulating cyclin D1.

p21 and p27 prevent cell cycle progression by binding to cyclin-CDK complexes [20]. They are regarded as tumor suppressors as their upregulation inhibits proliferation of many cancer cells [21]. Diosgenin treatment increases expression of p21 and p27 in primary human thyrocytes, indicating that expression of p21 and p27 might associate diosgenin-induced cell cycle arrest.

PI3K/Akt signaling pathway was involved in biological processes such as metabolism, proliferation of cells and thyroid carcinogenesis [22]. Downregulation of the pathway has been reported to suppress cancer progression [23].

Inhibition of PI3K/Akt pathway by LY294002 upregulated expression of p21 and p27 [24] and caused to cell cycle arrest [25]. Our results showed that diosgenin treatment inhibited phosphorylation of Akt, but did not alter the expression levels of several proteins (MEK, pMEK, ERK, p-ERK). The results suggest that deactivating PI3K/Akt pathway was involved in diosgenin-triggered cell cycle arrest in primary human thyrocytes, accompanied by an increase in the expression level of p21 and p27.

\section{CONCLUSION}

The findings of this work indicate that diosgenin treatment decreases proliferation of primary human thyrocytes and triggers $\mathrm{G}_{0} / \mathrm{G}_{1}$ arrest by downregulating cyclin D1. Deactivation of Akt and increased expression of p21 and p27 are involved in the anti-proliferative activitm $y$ of diosgenin. Thus, diosgenin and its derivatives may have potentials for development as therapies for GD and other proliferative thyroid diseases.

\section{DECLARATIONS}

\section{Acknowledgement}

This work was supported by Yancheng City Medical Science and Technology Development Project (no. YK2014006), Jiangsu Province, China.

\section{Conflict of Interest}

No conflict of interest associated with this work.

\section{Contribution of Authors}

The authors declare that this work was done by the authors named in this article and all liabilities pertaining to claims relating to the content of this article will be borne by them.

\section{REFERENCES}

1. Morshed SA, Davies TF. Graves' Disease Mechanisms: The Role of Stimulating, Blocking, and Cleavage Region TSH Receptor Antibodies. Horm Metab Res 2015; 47(10): 727-734.

2. Burch HB, Burman KD, Cooper DS. A 2011 survey of clinical practice patterns in the management of Graves' disease. J Clin Endocrinol Metab 2012; 97: 4549-58.

3. Vitti $P$, Rago $T$, Chiovato $L$, Pallini $S$, Santini $F$, Fiore $E$, Rocchi $R$, Martino $E$, Pinchera $A$. Clinical features of patients with Graves' disease undergoing remission after antithyroid drug treatment. Thyroid 1997; 7: 369-75.

4. Puri HS, Jefferies TM, Hardman $R$, Diosgenin and yamogenin levels in some Indian plant samples, Planta Med 1967; 30: 118-121

5. Hooker E. Final report of the amended safety assessment of Dioscorea Villosa (Wild Yam) root extract. Int J Toxicol 2004; 23: 49-54.

6. Sharma RD, Raghuram TC, Rao NS. Effect of fenugreek seeds on blood glucose and serum lipids in type I diabetes. Eur J Clin Nutr 1990; 44: 301-306.

7. Akinori Haratake, Daisuke Watase, Shuichi Setoguchi. Effect of orally ingested diosgenin into diet on skin collagen content in a low collagen skin mouse model and its mechanism of action. Life Sciences 2017; 174: 77-82.

8. Sauvaire $Y$, Ribes G, Baccou JC, Loubatieeres-Mariani MM. Implication of steroid saponins and sapogenins in the hypocholesterolemic effect of fenugreek. Lipids 1991; 26: 191-197.

9. Pandian RS, Anuradha CV, Viswanathan $P$. Gastroprotective effect of fenugreek seeds (Trigonella 
foenum graecum) on experimental gastric ulcer in rats. $J$ Ethnopharmacol 2002; 81: 393-397.

10. CHEN Yan, TANG You-Mei, YU Su-Lan, HAN Yu-Wei, KOU Jun-Ping ${ }^{*}$, LIU Bao-Lin, YU Bo-Yang. Advances in the pharmacological activities and mechanisms of diosgenin. Chin J Nat Med 2015; 13(8): 578-587.

11. Wang WC, Liu SF, Chang WT, Yang YL. The effects of diosgenin in the regulation of renal proximal tubular fibrosis. Exp Cell Res 2014; 323(2): 255-262.

12. Dezhi Bian, Zhiwei Li, Hongyan Ma. Effects of Diosgenin on Cell Proliferation Induced by IGF-1 in Primary Human Thyrocytes. Arch Pharm Res 2011; 34(6): 997-1005.

13. European Union Commission Regulation. EC 86/609/EEC. Off. J. Eur. Union 1986, L358, 1-28.

14. National Institutes of Health. Guidelines regarding the care and use of animals for experimental procedures (LIN-DL-11) NIH Publication No.8 5-23, revised 1985

15. G Bhuvanalakshmi, Basappa, Kanchugarakoppa $S$ Rangappa, Arun Dharmarajan, Gautam Sethi, Alan $P$ Kumar, Sudha Warrier. Breast cancer stem-like cells are inhibited by diosgenin, a steroidal saponin, by the attenuation of the Wnt $\beta$-catenin signaling via the Wnt antagonist secreted frizzled related protein-4. Frontiers in Pharmacology 2017;8(124)1-14.

16. Lin SS, Huang HP, Yang JS, Wu JY, Hsia TC, Lin CC, Lin CW, Kuo CL, Gibson Wood W, Chung JG. DNA damage and endoplasmic reticulum stress mediated curcumin-induced cell cycle arrest and apoptosis in human lung carcinoma A-549 cells through the activation caspases cascade- and mitochondrialdependent pathway. Cancer Lett 2008; 272: 77-90.

17. Beier F, Lee RJ, Taylor AC. Identification of the cyclin D1 gene as a target of activating transcription factor 2 in chondrocytes. Proc Natl Acad Sci USA 1999; 96(4): 1433-1438.
18. Corbiere C, Liagre B, Bianchi A, Bordji K, Dauca M, Netter $P$, Beneytout JL. Different contribution of apoptosis to the antiproliferative effects of diosgenin and other plant steroids, hecogenin and tigogenin, on human 1547 osteosarcoma cells. Int J Oncol 2003; 22(4): 899905.

19. Kim SM, Lee EJ, Lee JH, Yang WM, Nam D, Lee JH, Lee SG, Um JY, Shim BS1, Ahn KS. Simvastatin in combination with bergamottin potentiates TNF-induced apoptosis through modulation of NF-KB signalling pathway in human chronic myelogenous leukaemia. Pharm Biol 2016; 54(10): 2050-60.

20. Lee E, Kwak GH, Kamble K and Kim HY. Methionine sulfoxide reductase $B 3$ deficiency inhibits cell growth through the activation of p53-p21 and p27 pathways. Arch Biochem Biophys 2014; 547: 1-5.

21. Masgras I, Carrera $S$, de Verdier PJ, et al. Reactive oxygen species and mitochondrial sensitivity to oxidative stress determine induction of cancer cell death by p21. $J$ Biol Chem 2012; 287: 98459854.

22. Xing M. Genetic alterations in the phosphatidylinositol-3 kinase/Akt pathway in thyroid cancer. Thyroid 2010; 20 (7): 697-706.

23. Pal I, Mandal M. PI3K and Akt as molecular targets for cancer therapy: current clinical outcomes. Acta Pharmacol Sin 2012; 33: 1441-1458.

24. Izutani $Y$, Yogosawa S, Sowa $Y$ and Sakai T. Brassinin induces $G 1$ phase arrest through increase of p21 and p27 by inhibition of the phosphatidylinositol 3-kinase signaling pathway in human colon cancer cells. Int $J$ Oncol 2012; 40: 816-824.

25. Georgakis GV, Li Y, Rassidakis GZ, Medeiros LJ, Mills $G B$ and Younes A. Inhibition of the phosphatidylinositol3 kinase/Akt promotes $G 1$ cell cycle arrest and apoptosis in Hodgkin lymphoma. Br J Haematol 2006; 132: $503-511$. 